$\begin{array}{ll}\text { Volume } & : 7 \\ \text { Nomor } & : 3 \\ \text { Bulan } & : \text { Agustus } \\ \text { Tahun } & : 2021\end{array}$

\title{
Aktualisasi Nilai-nilai Pancasila dalam Upacara Adat Kebo-keboan (Studi Kasus Upacara Adat Kebo-keboan Alasmalang)
}

\author{
Yuli Kartika Efendi \\ Umi Farida \\ Universitas PGRI Banyuwangi \\ Pos-el: yulikartikaefendi@gmail.com
}

DOI: 10.32884 /ideas.v7i3.421

\begin{abstract}
Abstrak
Nilai-nilai Pancasila mulai menghilang dari kepribadian masyarakat Indonesia. Perlu adanya penerapan nilainilai Pancasila dalam kehidupan sehari-hari masyarakat yang diwujudkan melalui kebudayaan. Tujuan penelitian ini untuk mengetahui aktualisasi nilai-nilai Pancasila dalam upacara adat Kebo-keboan di desa Alasmalang. Penelitian ini menggunakan metode kualitatif deskriptif agar peneliti mengetahui secara langsung aktualisasi nilai-nilai Pancasila dalam upacara adat Kebo-keboan. Pengumpulan data dilakukan dengan cara observasi, wawancara, dan dokumentasi. Hasil penelitian menunjukkan bahwa dalam pelaksanaan upacara adat Kebokeboan relevan dengan nilai-nilai Pancasila. Aktualisasi lima sila dari Pancasila tercermin dalam setiap prosesi upacara adat Kebo-keboan yakni nilai ketuhanan, nilai kemanusiaan, nilai persatuan, dan gotong royong, nilai musyawarah mufakat dan solidaritas, serta cinta tanah air.
\end{abstract}

\section{Kata Kunci}

nilai-nilai pancasila, kebudayaan, upacara adat kebo-keboan

\begin{abstract}
The value of Pancasila slowly has disappeared from the personality of Indonesia people. The value of Pancasila needs to be applicated in the daily life which embodied in culture. This research aims to know the actualization of value of Pancasila with in Kebo-keboan ritual in Alasmalang village. This research using descriptive qualitative method to know actualization value of Pancasila directly in ritual Kebo-keboan. Data collect taken by observation, interview, and documentation. The result of this research showing that Kebo-keboan ritual has relevance with value of Pancasila. Actualization of fives principle of Pancasila reflected in every step Kebokeboan ritual procession especially value of God, humanity, unity and cooperation, deliberation and consensus, solidarity, and nationalism.
\end{abstract}

\section{Keywords}

value of Pancasila, culture, ritual kebo-keboan

\section{Pendahuluan}

Pancasila sebagai dasar negara memiliki peranan penting dalam setiap aspek kehidupan masyarakat Indonesia. Pancasila merupakan perumusan dari pedoman kehidupan berbangsa dan bernegara bagi masyarakat Indonesia (Yuliastuti, Eka; Jafar 2020). Sedangkan sebagai pandangan hidup bangsa Pancasila memiliki arti bahwa Pancasila menjadi pedoman bagi setiap perilaku bangsa Indonesia (Antari 2018). Namun, pada realitanya masyarakat Indonesia dalam berperilaku di kehidupan sosial semakin jauh dari nilai-nilai Pancasila. Hal tersebut dapat dilihat dari masih adanya sikap intoleran dan radikalisme di kalangan masyarakat.

Menurut Eddy (2018) Pancasila sering mengalami penyimpangan dalam aktualisasi nilai-nilainya sepanjang perjalanan berbangsa dan bernegara. Penyimpangan pengamalan Pancasila tersebut dapat berupa pengurangan, penambahan, dan penyimpangan dari makna yang seharusnya. Seiring dengan hal tersebut sering pula terjadi pelurusan kembali terhadap aktualisasi nilai-nilai Pancasila.

Membumikan dan mengamalkan nilai-nilai Pancasila harus selalu diupayakan dan dilaksanakan agar lebih memahami, mengerti, dan mampu mengamalkan dalam kehidupan sehari-hari (Adha \& Susanto 2020). Berbagai upaya pemerintah untuk menumbuhkan nilai-nilai Pancasila dalam diri masyarakat Indonesia sering digalakkan. Mulai dari penanaman nilai-nilai Pancasila di bangku sekolah dasar hingga perguruan tinggi, serta workshop mengenai wawasan kebangsaan. 
Internalisasi nilai-nilai Pancasila dalam kebudayaan juga menjadi salah satu cara dalam menumbuhkan nilai-nilai Pancasila di masyarakat. Hal ini selaras dengan pernyataan Febriansyah, Alfiandra, \& Faisal (2018) yang menyatakan bahwa "salah satu unsur utama yang menjadi sumber bahan dari Pancasila yakni kebudayaan”. Nilai-nilai yang terkandung pada Pancasila merupakan kristalisasi dari adat-istiadat, kebiasaan, sosial, kebudayaan serta agama-agama yang tumbuh di Indonesia (Pingge \& Aingu 2021). Dapat dikatakan Pancasila lahir dari nilai-nilai kebudayaan suku bangsa Indonesia. Sehingga dari kebudayaan yang sangat dekat dengan masyarakat diharapkan dapat menyadarkan kembali pentingnya penerapan nilai-nilai Pancasila dalam kehidupan berbangsa dan bernegara.

Penerapan dari nilai dasar dan nilai instrumental Pancasila dalam kehidupan nyata disebut nilai praksis. Kajian mengenai nilai praksis Pancasila dalam budaya Seni Tutur Tadut di kota Pagaralam mencatat ada 47 butir penggalan kalimat yang mengandung nilai praksis Pancasila dan nilai Sila ke-1 menjadi nilai yang paling dominan dengan besaran prosentase 61,7\% (Febriansyah, Dicky; Alfiandra \& Faisal 2018). Tidak hanya pada seni tutur nilai-nilai Pancasila juga pernah dikaji dalam seni tari yaitu Tari Kecak. Antari (2018) menyatakan nilai-nilai Pancasila yang terkandung pada tari Kecak adalah nilai keTuhanan, nilai persatuan dan gotong royang, nilai perbedaan, nilai cinta terhadap bangsa dan tanah air.

Selain dua kajian tersebut, Arianto \& Yurnalis (2015) juga meneliti mengenai nilai-nilai Pancasila yang terkandung dalam upacara adat perkawinan masyarakat Petalangan di Kecamatan Bandar dan hasilnya upacara adat perkawinan tersebut memiliki nilai ketuhanan, nilai kemanusiaan, nilai kesatuan, nilai musyawarah, dan nilai sosial. Kebudayaan Indonesia memiliki berbagai wujud antara lain rumah adat, upacara adat, pakaian tradisional, tarian adat, alat musik dan lagu tradisional, senjata tradisional, dan makanan khas. Salah satu kebudayaan yang menjadi wadah interaksi masyarakat yaitu upacara adat.

Setiap daerah memiliki upacara adat yang berbeda dan memiliki ciri khas tertentu. Selaras dengan penelitian yang telah dilakukan sebelumnya peneliti ingin mengkaji nilai-nilai Pancasila pada Upacara Adat Kebo-keboan di desa Alasmalang Kabupaten Banyuwangi. Penelitian ini bertujuan untuk mengetahui aktualisasi nilai-nilai Pancasila yang terdapat pada Upacara Adat Kebo-keboan di desa Alasmalang Kabupaten Banyuwangi.

\section{Metode}

Penelitian ini menggunakan pendekatan kualitatif deskriptif. Menurut Moleong penelitian kualitatif adalah penelitian yang memiliki maksud untuk memahami fenomena yang dialami oleh subyek penelitian misalnya persepsi, perilaku, tindakan secara holistik dan dengan cara deskriptif (Bahrudin, Febrian Alwan; Ngulwiyah 2017). Pendekatan kualitatif deskriptif digunakan agar peneliti mendapatkan data yang nyata terjadi di lapangan dan mengetahui secara langsung tentang implementasi nilai-nilai Pancasila dalam upacara adat Kebo-keboan.

Penelitian ini dilakukan di Desa Alasmalang Kabupaten Banyuwangi Provinsi Jawa Timur. Teknik pengumpulan data yang digunakan dalam penelitian ini yaitu wawancara, observasi, dan dokumentasi. Pemilihan narasumber untuk wawancara ditentukan dengan cara snowball sampling yang terdiri dari Pemangku Adat, Kepala Desa, dan tiga masyarakat desa Alasmalang. Observasi dilakukan pada saat upacara adat Kebo-keboan dilaksanakan dari proses persiapan hingga upacara adat selesai. Dokumentasi dilakukan dengan melihat dokumentasi yang dimiliki desa Alasmalang, mengakses buku serta jurnal-jurnal yang memperkaya literatur mengenai nilai-nilai Pancasila dalam upacara adat. Data yang diperoleh kemudian dianalisis secara langsung dengan mereduksi, menyajikan dan menarikan kesimpulan.

\section{Hasil dan Pembahasan}

\section{Hasil}

\section{Upacara Adat Kebo-keboan}

Banyuwangi ialah kabupaten terluas di pulau Jawa dengan kondisi ekologis berupa gunung dan pegunungan di sebalah utara dan barat, serta pantai di sebelah timur dan selatan. Kondisi ekologis tersebut membuat masyarakat Banyuwangi bermatapencaharian sebagai petani dan nelayan. Kondisi ini pula yang melahirkan budaya agraris dan pesisir. Masyarakat Banyuwangi khususnya suku Using (suku asli Banyuwangi) mewujudkan budaya agraris dalam bentuk upacara adat bersih desa di beberapa wilayah sebagai ungkapan syukur terhadap Tuhan Yang Maha Esa atas panen yang melimpah. Sedangkan budaya pesisir diwujudkan 
dalam bentuk larung sesaji di beberapa pantai yang diyakini membawa berkah bagi nelayan.

Masyarakat suku Using memiliki kepercayaan animisme dan dinamisme. Denti \& Legowo (2015) mengemukakan bahwa masyarakat suku Using masih sangat percaya dengan kekuatan mistik dan memegang teguh ajaran nenek moyang terdahulu. Hal tersebut tampak dalam kehidupan masyarakat suku Using di waktu-waktu tertentu. Kepercayaan terhadap roh nenek moyang juga dapat dilihat dari kegiatan pertanian ketika musim tanam maupun musim panen. Di desa Alasmalang masyarakat suku Using yang dahulu nenek moyangnya didominasi sebagai petani mengadakan upacara adat Kebo-keboan.

Upacara adat Kebo-keboan bertujuan untuk mengusir wabah penyakit dan memohon perlindungan kepada Tuhan Yang Maha Esa agar terhindar dari musibah dan bencana serta sebagai perwujudan ucapan syukur atas panen yang berlimpah. Hal tersebut seperti yang dikemukakan oleh Sekertaris Desa Alasmalang berikut ini.

"Upacara Adat Kebo-keboan merupakan upacara ritual bentuk syukur masyarakat atas hasil pertaniannya dan juga untuk menghidupkan tradisi adat yang sudah turun temurun. Juga untuk permohonan agar kedepannya diberikan keselamatan" (Wawancara dengan Heru Susianto, 2020).

Upacara adat ini disebut Kebo-keboan karena masyarakat yang berperan di dalam upacara dirias sedemikian rupa menyerupai kerbau atau dalam bahasa jawa kebo. Denti \& Legowo (2015) juga mengemukakan penggunaan Kebo-keboan juga berkaitan dengan kepercayaan masyarakat suku Using mengenai karakter binatang yang menyatu dalam jiwa manusia. Hal tersebut juga didasari dari asal-mula upacara ini terbentuk yang dikemukakan oleh warga desa Alasmalang.

"Pelaksanaan adat ini berasal dari cerita ribuan tahun silam ada sebuah penyakit pagebluk semacam pandemi di bidang pertanian yang menimpa masyarakat tani dan kerbau artinya masyarakat banyak informasi malamnya, sakit, paginya meninggal terus terjadi kerbaunya juga begitu. Kenapa kerbaunya juga begitu karna kerbau itu binatang yang di agungkan oleh masyarakat disini dalam rangka menopang kehidupan yaitu ekonomi dan kehidupaan untuk bercocok tanam kerbau segala-galanya. Disini dulu gudangnya kerbau, sekarang tinggal dua kerbaunya, karna peradapan jaman peran kerbau di gantikan oleh mesin, tapi pada saat itu di sini kerbau bisa membantu warga bercocok tanam mengolah pertanian. Kemudian terkait pagebluk tadi pertaniannya terganggu dan mendapat hama tikus dan hama yang lain, kemudian mbah buyut Karti menginisiasi mengadakan ritual” (Wawancara dengan Saripin, 2020).

Masyarakat desa Alasmalang hingga saat ini melestarikan upacara adat Kebo-keboan karena mereka meyakini jika tidak menjalankan upacara adat Kebo-keboan desa akan mengalami musibah atau bencana. Sehingga dari kedua pernyataan sebelumnya dapat disimpulkan bahwa upacara Upacara adat Kebo-keboan merupakan upacara adat bersih desa yang rutin dilakukan setiap bulan suro sebagai bentuk doa memohon perlingdungan kepada Tuhan Yang Maha Esa dari musibah maupun wabah penyakit. Selain itu juga sebagai ungkapan rasa syukur atas hasil panen yang melimpah serta harapan agar hasil panen tahun berikutnya juga melipah.

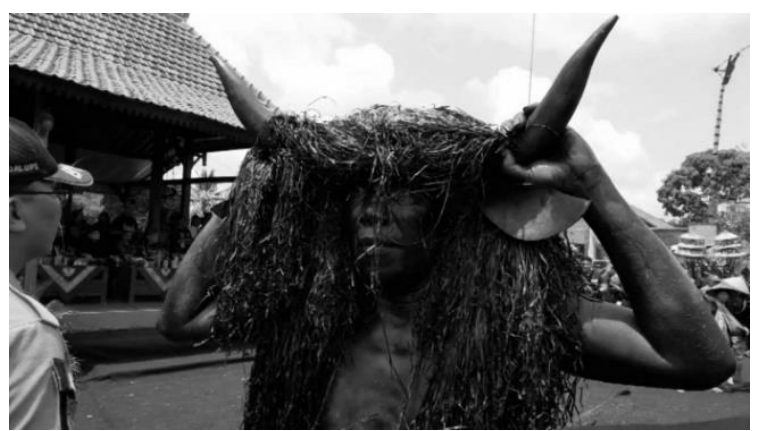

Gambar 1 Pemeran Kebo-Keboan

\section{Pelaksanaan Upacara Adat Kebo-keboan}

Upacara adat Kebo-keboan mempunyai tiga tahapan meliputi pra acara, acara inti dan acara akhir atau penutupan. 


\section{Pra-Acara}

Persiapan upacara adat Kebo-keboan dimulai satu bulan sebelum bulan suro diawali dengan musyawarah desa untuk menentukan ketua panitia beserta jajarannya. Musyawarah atau dalam bahasa jawa rembugan diikuti oleh masyarakat desa Alasmalang terutama dusun Krajan, Kepala Desa, dan lembaga Adat. Selain pemilihan panitia masyarakat juga menentukan pemeran Dewi Sri.

Masyarakat desa Alasmalang mengawali upacara adat Kebo-keboan dengan selamatan pembuko. Masyarakat desa Alasmalang khususnya dusun Krajan mulai memasak nasi, lauk pauk, dan kue-kue untuk dihantarkan ke sanak famili handai taulan di luar desa Alasmalang. Selamatan ini juga disebut sebagai sedekah bumi artinya sedekah dari hasil bumi yang didapatkan masyarakat desa Alasmalang. Sedekah bumi ini bertujuan agar hasil bumi dari desa Alasmalang dapat dirasakan oleh masyarakat luas.

\section{Acara Inti}

Usai selamatan pembuko masyarakat desa beserta panitia bergotong royong membuat kereta Dewi Sri dan menghias panggung hiburan. Masyarakat desa saling bahu-membahu dan bersinergi untuk dapat mewujudkan upacara adat yang khidmat. Memasuki acara inti masyarakat desa Alasmalang memulai acara selamatan kampung. Seluruh lapisan masyarakat desa Alasmalang duduk bersimpuh di sepanjang jalan dusun Krajan kemudian pemangku adat memimpin doa bersama, istighosah, dan santunan anak yatim sebagai wujud ucapan syukur kepada Tuhan Yang Maha Esa serta memohon perlindungan agar masyarakat desa Alasmalang terhindar dari wabah penyakit dan bencana.

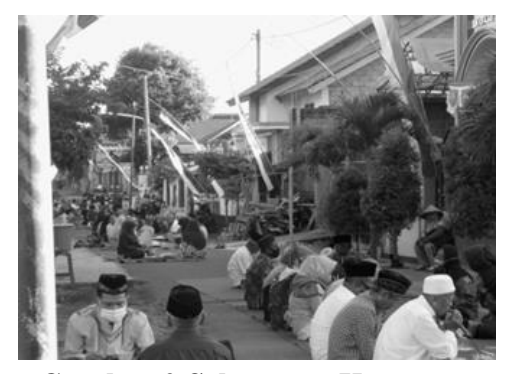

Gambar 2 Selamatan Kampung

Setelah selamatan kampung dilanjutkan dengan pemasangan gapura palawija yang terdiri dari polo pendem, polo kesimpar, dan polo gemantung. Masyarakat desa dari usia muda hingga tua, laki-laki maupun perempuan dan dari berbagai latar belakang status sosial bergotong royong membuat gapura palawija di empat penjuru desa. Sikap gotong royong masyarakat desa tidak dapat dipungkiri nampak sepanjang berlangsungnya upacara adat Kebokeboan. Meskipun saat ini terjadi wabah COVID-19, masyarakat desa Alasmalang tetap melaksanakan upacara adat Kebo-keboan dengan mematuhi protokol kesehatan yang telah dianjurkan oleh pemerintah.

Memasuki acara puncak yakni ijab qobul Kebo-keboan, masyarakat yang berperan menjadi kebo akan diijabkan. Masyarakat desa mempersiapkan rangkaian ritual dan selamatan yang terdiri dari 12 porsi petek ingkung beserta tumpengnya sebagai simbol adanya 12 bulan dalam setahun, 5 porsi jenang sengkolo sebagai simbol limo pasaran dalam seminggu pada kalender Jawa, dan 7 porsi jenang suro sebagai simbol tujuh hari dalam seminggu pada kalender nasional. Setelah ijab qobul pemeran Kebo-keboan akan diarak keliling kampung atau disebut ider bumi.

Pawai ider bumi merupakan ritual mengelilingi dusun Krajan melalui jalur empat penjuru yaitu timur, barat, utara, dan selatan yang dimulai dari arah barat sebagai titik sentral berkumpul (Lestari 2020b). Pawai ini diiringi pemeran Dewi Sri yang menunggangi kereta dan berbagai peralatan tanam serta tabuhan musik khas Using. Kebokeboan diarak menuju empat pepunden atau penjuru. Pada setiap pepunden pemangku adat akan meletakkan sesaji yang berisi dua tandan pisang, satu butir kelapa, gula, minyak, dan benih padi sebagai simbol dimulainya musim tanam yang akan datang.

\section{Acara Penutup}

Setelah seluruh rangkaian Kebo-keboan selesai acara penutup yakni pagelaran wayang kulit yang melakonkan Dewi Sri. Pagelaran ini sebagai ritual tenger ngeruat Dewi Sri yang menjadi simbol kemakmuran petani. Tidak hanya pagelaran wayang kulit yang ditampilkan, kesenian lain berupa tari-tarian dan lagu-lagu daerah juga ditampilkan. Hal ini bertujuan untuk melestarikan budaya Indonesia agar generasi muda mengenal seni wayang kulit dan mencintai kesenian tanah air. 


$\begin{array}{ll}\text { Volume } & : 7 \\ \text { Nomor } & : 3 \\ \text { Bulan } & : \text { Agustus } \\ \text { Tahun } & : 2021\end{array}$

Dari serangkaian upacara adat Kebo-keboan tersebut, kita dapat melihat sebuah rangkaian acara yang telah tersusun dengan memberdayakan seluruh kekuatan masyarakat untuk melaksanakan kegiatan tersebut. Upacara adat Kebo-keboan tidak hanya diikuti masyarakat desa Alasmalang tetapi juga masyarakat dari luar desa Alasmalang. Saat ini upacara adat Kebo-keboan masuk dalam Calender of Event serta dijadikan sebagai salah satu potensi pariwisata di kabupaten Banyuwangi untuk menjaga kelestarian kebudayaan daerah (Lestari 2020a).

\section{Pembahasan}

Masyarakat desa Alasmalang telah mengamalkan nilai-nilai Pancasila dalam kegiatan upacara adat Kebokeboan. Tujuan diadakannya upacara adat Kebo-keboan merupakan wujud dari nilai Ketuhanan. Masyarakat meyakini bahwa tidak ada Dzat yang lebih berkuasa selain Tuhan Yang Maha Esa.

Nilai kemanusiaan membuat masyarakat desa Alasmalang tidak lupa untuk sedekah atas limpahan panen yang dihasilkan. Sedekah sebagai wujud rasa kemanusiaan dan solidaritas sosial yang selaras dengan sila kedua. Masyarakat desa pun membuka diri dengan masyarakat luar desa dengan mengijinkan masyarakat luar untuk ikut berpartisipasi menjadi penonton ataupun menjadi pemeran Kebo-keboan .

Partisipasi dari berbagai kalangan tanpa memandang ras, suku, dan agama menjadikan upacara adat Kebo-keboan sebagai salah satu wadah bersatunya masyarakat. Semangat gotong royong tercermin dari persiapan hingga terlaksananya upacara adat yang khidmat dan lancar. Pengambilan keputusan masih menjunjung tinggi nilai permusyarawatan yang tertuang dalam sila ke empat. Nilai musyawarah dan mufakat tidak hanya menjadi tatanan verbal semata namun diaktualisasikan dalam pengambilan keputusan di kehidupan nyata dan faktual (Paramita 2020).

Pengenalan budaya dan kearifan lokal sebagai salah satu upaya penanaman karakter Pancasila. Pembangunan karakter berbasis nilai-nilai budaya daerah dengan tujuan untuk menemukan kembali nilai-nilai kearifan lokal sebagai sumber daya menumbuhkan nasionalisme bangsa Indonesia (Yuliastuti, Eka; Jafar 2020). Rasa cinta tanah air ditumbuhkan dengan mempertunjukan ragam kesenian daerah. Dapat dikatakan masyarakat desa Alasmalang sudah berpancasila didalam adat kebudayaan mereka.

\section{Simpulan}

Berdasarkan pemaparan yang telah disampaikan sebelumnya dapat disimpulkan bahwa dalam upacara adat Kebo-keboan di desa Alasmalang sangat relevan dengan nilai-nilai Pancasila. Aktualisasi lima sila Pancasila dalam upacara adat Kebo-keboan tercermin dari persiapan awal hingga upacara selesai. Hal tersebut menjadi salah satu bentuk sikap atau karakter yang lebih mudah dipahami dan dikenali oleh masyarakat.

Peneliti berharap dengan masuknya budaya global tidak melunturkan karakter budaya asli Indonesia. Nilai-nilai Pancasila yang terkandung dalam budaya Indonesia tidak hanya dimaknai sebatas saat kebudayaan tersebut dipertunjukkan tetapi juga diaplikasikan dalam kehidupan sosial masyarakat. Implementasi nilai-nilai Pancasila dalam kegiatan sosial, keagamaan, dan kebudayaan sangat penting untuk mengembalikan fitrah bangsa Indonesia.

\section{Daftar Rujukan}

Adha, Muhammad Mona, and Erwin Susanto. 2020. "Kekuatan Nilai-Nilai Pancasila Dalam Membangun Kepribadian Masyarakat Indonesia." Al-Adabiya: Jurnal Kebudayaan Dan Keagamaan 15(1):121-38.

Antari, Luh Putu Swandewi. 2018. "Implementasi Nilai-Nilai Pancasila Pada Tari Kecak.” Jurnal Stilistika 7(1):57-74. doi: $10.5281 /$ zenodo.3895330.

Arianto, Jumili; Yurnalis, Afrizal. 2015. "Studi Tentang Nilai-Nilai Pancasila Yang Terkandung Dalam Upacara Adat Perkawinan Masyarakat Petalangan Di Kec. Bandar-Petalangan-Pelalawan.” Perspektif Pendidikan Dan Keguruan VI(11):1-10.

Bahrudin, Febrian Alwan; Ngulwiyah, Istingatul. 2017. "Implementasi Nilai-Nilai Karakter Budaya Bangsa (Studi Kasus Di SMA Negeri 15 Pandeglang Banten)." Untirta Civic Education Journal 36(4):71-85.

Denti, Hervinda Fran's, and Martinus Legowo. 2015. "Makna Upacara Adat Keboan (Studi Interaksionisme Simbolik Pada Masyarakat Desa Aliyan Kecamatan Rogojampi Kabupaten Banyuwangi).” Jurnal Paradigma 3(2):1-9.

Eddy, I. Wayan Tagel. 2018. "Aktualisasi Nilai Pancasila Dalam Kehidupan Berbangsa Dan Bernegara." Dharmasmrti I(18):1-134

Febriansyah, Dicky; Alfiandra, Alfiandra;, and Emil El Faisal. 2018. "Analisis Nilai-Nilai Pancasila Yang Terkandung Di Dalam Seni Tutur Tadut (Studi Kasus Tadut Di Kota Pagaralam)." Jurnal Bhinneka Tunggal Ika 5(1):35-51.

Lestari, Dinna Eka Graha. 2020a. "Dinamika Perubahan Sosial Upacara Adat Kebo-Keboan Pada Masyarakat Using Desa Alasmalang Kecamatan Singojuruh Kabupaten Banyuwangi." Cakrawala 14(14):198-220. doi: 


\begin{tabular}{c|ll} 
LE-ISSH: 2656-940X & Volume & $: 7$ \\
Nomor & $: 3$ \\
P-ISSH: 2442-367K & Bulan & $:$ Agustus \\
URL:jurnal.ideaspublishing.co.id & Tahun & $: 2021$
\end{tabular}

10.32781/cakrawala.v14i2.349.

Lestari, Dinna Eka Graha. 2020b. "Upacara Adat Kebo-Keboan Desa Alas Malang Kecamatan Singojuruh Kabupaten Banyuwangi." An-Nas: Jurnal Humaniora 4(2):30-45.

Paramita, I. Gusti Agung. 2020. “Aktualisasi Pancasila Dalam Budaya Masyarakat Bali Aga.”Vidya Wertta 3(2):1-17.

Pingge, Heronimus Delu, and Rahel Maga Aingu. 2021. "Studi Etnopedagogi Nilai-Nilai Sila Pancasila Pada Budaya Lokal Masyarakat Adat Sumba." Jurnal Papeda: Jurnal Publikasi Pendidikan Dasar 3(1):16-22. doi: 10.36232/jurnalpendidikandasar.v3i1.770.

Yuliastuti, Eka; Jafar, Wahyu Abdul. 2020. "Aktualisasi Nilai Pancasila Dalam Acara Adat Sammilan Pada Masyarakat Adat Magho Sekappung Libo.” AL-IMARAH: Jurnal Pemerintahan Dan Politik Islam 5(1):1-19. 